\title{
Cannabinoid Receptor-1 Up-regulation in Azoxymethane (AOM)-treated Mice After Dietary Treatment with Quercetin
}

\author{
VALERIA TUTINO ${ }^{1}$, VALENTINA DE NUNZIO ${ }^{1}$, ANGELA TAFARO ${ }^{2}$, GIUSY BIANCO $^{2}$, \\ ISABELLA GIGANTE ${ }^{2}$, MARIA PRINCIPIA SCAVO $^{3}$, ROSALBA D'ALESSANDRO $^{4}$, \\ MARIA GRAZIA REFOLO ${ }^{4}$, CATERINA MESSA ${ }^{4}$, MARIA GABRIELLA CARUSO ${ }^{1}$ and MARIA NOTARNICOLA ${ }^{1}$ \\ ${ }^{1}$ Laboratory of Nutritional Biochemistry, ${ }^{2}$ Animal Facility, ${ }^{3}$ Laboratory of Personalized Medicine, \\ ${ }^{4}$ Laboratory of Cellular and Molecular Biology, \\ National Institute of Gastroenterology-Research Hospital, Castellana Grotte, Bari, Italy
}

\begin{abstract}
Background/Aim: The expression of cannabinoid receptor-1 $(C B 1-R)$ seems to be modulated by bioactive natural components such as the flavonoid quercetin. The aim of this study was to determine in an animal model of induced-colon cancer, whether quercetin inhibits colon carcinogenesis through changes in the expression of CB1-R. Materials and Methods: $C 57 B L / 6 J$ male mice were randomly assigned to standard diet or experimental diet supplemented with $0.5 \%$ quercetin. Azoxymethane (AOM) (10 mg/kg body weight) or saline solution (PBS) was intraperitoneally injected, once weekly for 6 weeks. Results: The diet supplemented with quercetin induced CB1-R gene expression and protein, inhibiting the protein levels of STAT3 and p-STAT3 (both mediators of cell proliferation). Dietary quercetin also caused a significant increase in Bax/Bcl2 ratio protein expression. Conclusion: The anti-proliferative and pro-apoptotic effects of quercetin in AOM-treated mice are mediated by induction of the protein and gene expression levels of $C B 1-R$.
\end{abstract}

Cannabinoids and their derivatives play a prominent role in physiological and pathophysiological processes of the gastrointestinal tract (1-3). Cannabinoid activity is regulated by the endocannabinoid system (ECS), which is comprised of receptors, such as cannabinoid receptor 1 (CB1-R), cannabinoid receptor 2 (CB2-R) and enzymes involved in endocannabinoids synthesis and degradation (4).

Many studies have investigated the effects of ECS in tumor development and progression (4-6). In particular,

Correspondence to: Maria Notarnicola, ScD, Laboratory of Nutritional Biochemistry, National Institute of Gastroenterology "S. de Bellis", Research Hospital, Castellana Grotte, Bari, Italy. Tel: +390804994342, e-mail: maria.notarnicola@irccsdebellis.it

Key Words: Cannabinoid receptor-1, quercetin, azoxymethane (AOM)-mouse model, colorectal cancer.
CB1-R has been shown to exert anti-inflammatory properties, accompanied by reduced proliferation and induction of apoptosis in tumor tissue (1). Several studies have reported a lack of the "protective action" of CB1-R in different types of cancer (7-9), suggesting a role for this receptor in the mechanisms controlling cell growth and proliferation. Previously, we demonstrated that anandamide, an endogenous agonist for CB1-R, inhibited the proliferation of colon cancer cell lines, through the modulation of cell cycle, in particular reducing the number of cells in the $S$ phase (10).

The expression of CB1-R seems to be modulated by bioactive natural components $(11,12)$ such as flavonoids. Quercetin belongs to polyphenolic flavonoids which are abundantly found in fruits and vegetables (13) and a large number of studies have demonstrated the anticancer properties of quercetin in in vitro and in vivo models (14-16). The daily administration of quercetin in mice has been demonstrated to have an anti-inflammatory effect in intestinal mucosa (17). Diets enriched in quercetin seem to create a pro-tolerogenic milieu in the gastrointestinal tract, able to maintain homeostasis and prevent chronic inflammatory disorders $(17,18)$. Quercetin has been demonstrated to suppress the levels of pro-inflammatory cyclooxygenase gene expression (COX-1 and COX-2) (19). Since inflammation in the colon is a key pathway in carcinogenesis, all biologically-active molecules able to reduce the inflammatory status of colonic mucosa are considered useful to confer cancer protection.

Our previous study demonstrated that anti-proliferative and pro-apoptotic effects of quercetin are mediated by CB1-R in human colon cancer cell lines (11). However, due to the complexity of the tumor microenvironment, these findings should be confirmed in vivo. Thus, the aim of this study was to determine in an animal model of induced colon cancer, whether quercetin inhibits colon carcinogenesis through changes in the expression of CB1-R and cell proliferation mediators. 


\section{Materials and Methods}

Animals. Forty C57BL/6J male mice (five-weeks-old) were randomly assigned to 1 of 4 experimental groups $(n=10$ mice per group). Control mice (ST+PBS) were fed a purified AIN-93M standard diet consisting of $12.5 \%$ protein, $12 \%$ soybean oil, $3 \%$ cellulose fiber and injected with saline solution (PBS); the Q+PBS group received the same standard diet supplemented with $0.5 \%$ quercetin and PBS by intraperitoneal injection; the ST+AOM group mice received the same standard diet and $\mathrm{AOM}$ at concentration of $10 \mathrm{mg} / \mathrm{kg}$ body weight by intraperitoneal injection; the $\mathrm{Q}+\mathrm{AOM}$ group was treated with the diet supplemented with $0.5 \%$ quercetin and received AOM by injection. AOM (10 mg/kg body weight) or saline solution (PBS) was intraperitoneally injected once a week for 6 weeks.

Diets were isocaloric and supplied as pellets (Mucedola Srl, Settimo Milanese, Italy). Food intake and body weight were measured weekly during the treatment period ( 35 weeks). All animals received care in compliance with the 'Guide for the Care and Use of Laboratory Animals'. The procedures relating to animal use were communicated to the Italian Ministry of Health and approved ( $\left.n^{\circ} 103 / 2016-\mathrm{PR}\right)$.

At sacrifice by cervical dislocation, the entire intestinal tract of all mice was immediately removed and washed with cold phosphate-buffered saline. The small intestine and colon were cut along the mesenteric insertion, placed on a paper strip at $0-4^{\circ} \mathrm{C}$ and analyzed through a stereomicroscope at $\times 3$ magnification. The number of mucosal lesions were calculated and part of the distal small intestine was immediately put in liquid nitrogen for real-time PCR and western blotting analyses, and the remaining part of the distal small intestine was fixed in $10 \%$ neutral buffered formalin for $24 \mathrm{~h}$ and embedded in paraffin in a 'Swiss roll' fashion.

CB1-R gene expression analysis. CB1 receptor gene expression levels were evaluated in distal intestinal tissue of mice by real-time RT-PCR method. Total RNA was extracted with TRI-Reagent (Mol. Res. Centre Inc. Cincinnati, OH, USA) following the manufacturer's instructions.

The reactions of RT and real time PCR were carried out using sense and antisense primers for $C B 1-R$ and $\beta$-actin genes (sense 5'-CCTG GGCTGGAACTGCAA-3' and antisense 5'-CCGAAGACGTCATAC ACCATGA-3'; sense 5'-GCCTCTGGTCGTACCACTGGC-3' and antisense 5'-AGGGAGGAAGAGGATGCGGCA, respectively). The $\beta$-actin gene was utilized as an internal control and was chosen as a reference gene. All expression data were normalized by dividing the CB1-R amount by the amount of $\beta$-actin. The specificity of PCR products was confirmed by gel electrophoresis.

Western blotting. Total proteins extracted from mice tissue samples were subjected to electrophoresis using SDS-PAGE gel. After the blotting onto a PVDF membrane (Bio-Rad Laboratories, Milan, Italy), the proteins were probed with the following primary antibodies: anti CB1-R (Abcam, Cambridge, UK), anti STAT3 and pSTAT3 (Immunological Sciences, Rome, Italy), anti Bax and Bcl2 (Santa Cruz Biotechnology, Dallas, TX, USA) and anti $\beta$-actin (Cell Signaling, Beverly, MA, USA). A horseradish peroxidaseconjugated secondary antibody (Bio-Rad Laboratories) was used and the signal of each protein, obtained using the Molecular Imager Chemidoc $^{\mathrm{TM}}$ (Bio-Rad Laboratories), was normalized against $\beta$ actin expression.
Histological studies. To evaluate the grade of dysplasia, hematoxylin and eosin-stained sections were examined blindly for the operator, respectively at $20 \times$ and $40 \times$ magnification. Dysplasia was defined as the occurrence of disorganized glandular architecture, depletion of mucin-producing cells and goblet cells, nuclear atypia and increased mitotic activity, and was graded mild, moderate or severe. The further presence of tissue hypercellularity, enhanced cell proliferation and degenerative/necrotic phenomena allow to recognize cancerous lesions, or inflammatory foci if present.

Statistical analysis. The significance of the differences among experimental groups was evaluated by one-way analysis of variance and Tukey's multiple comparison test. Differences were considered statistically significant with a $p$-value $<0.05$.

\section{Results}

After 35 weeks of dietary treatment, no difference in body weight was found among the experimental groups of mice (data not shown).

AOM treatment exerted a moderate grade of dysplasia, associated with an inflammatory infiltrate in intestinal samples of mice treated with standard diet (Figure 1A and B), whereas no macroscopical intestinal lesion was observed after quercetin treatment and the intestinal mucosa was normal (Figure 1C).

Dietary quercetin significantly induced CB1-R gene expression even if the AOM administration counteracted the effect of quercetin (Figure 2A). Lower levels of CB1-R mRNA were detected in mice treated with AOM when compared to mice injected with saline solution (PBS), $(p<0.001$, ANOVA and Tukey's multiple comparison test). The quercetin induction effect was more evident for CB1-R protein (Figure 2B), which was expressed at low levels in intestinal tissues of mice fed standard diet $(p<0.001$, ANOVA and Tukey's multiple comparison test).

To investigate the effects of quercetin on cell proliferation, STAT3 and p-STAT3 protein expressions were evaluated in intestinal tissues of the treated mice (Figure $3 \mathrm{~A}$ and B, respectively). The results showed that the protein levels of STAT3 and p-STAT3 were decreased in AOM mice after treatment with quercetin when compared to mice fed a standard diet. Higher levels of pSTAT3 protein were observed in mice treated with quercetin and injected with PBS (Figure 3B), demonstrating that the inhibition of p-STAT3 by quercetin was evident in AOM mice.

Figure 4 shows the Bax and $\mathrm{Bcl} 2$ protein levels detected in our samples. In AOM mice, dietary quercetin administration reduced the protein expression of $\mathrm{Bcl} 2$, causing a significant increase in the $\mathrm{Bax} / \mathrm{Bcl} 2$ ratio. This finding suggests that the anti-proliferative effect of flavonoid quercetin was mediated by a significant induction of apoptosis in mice intestinal mucosa. 

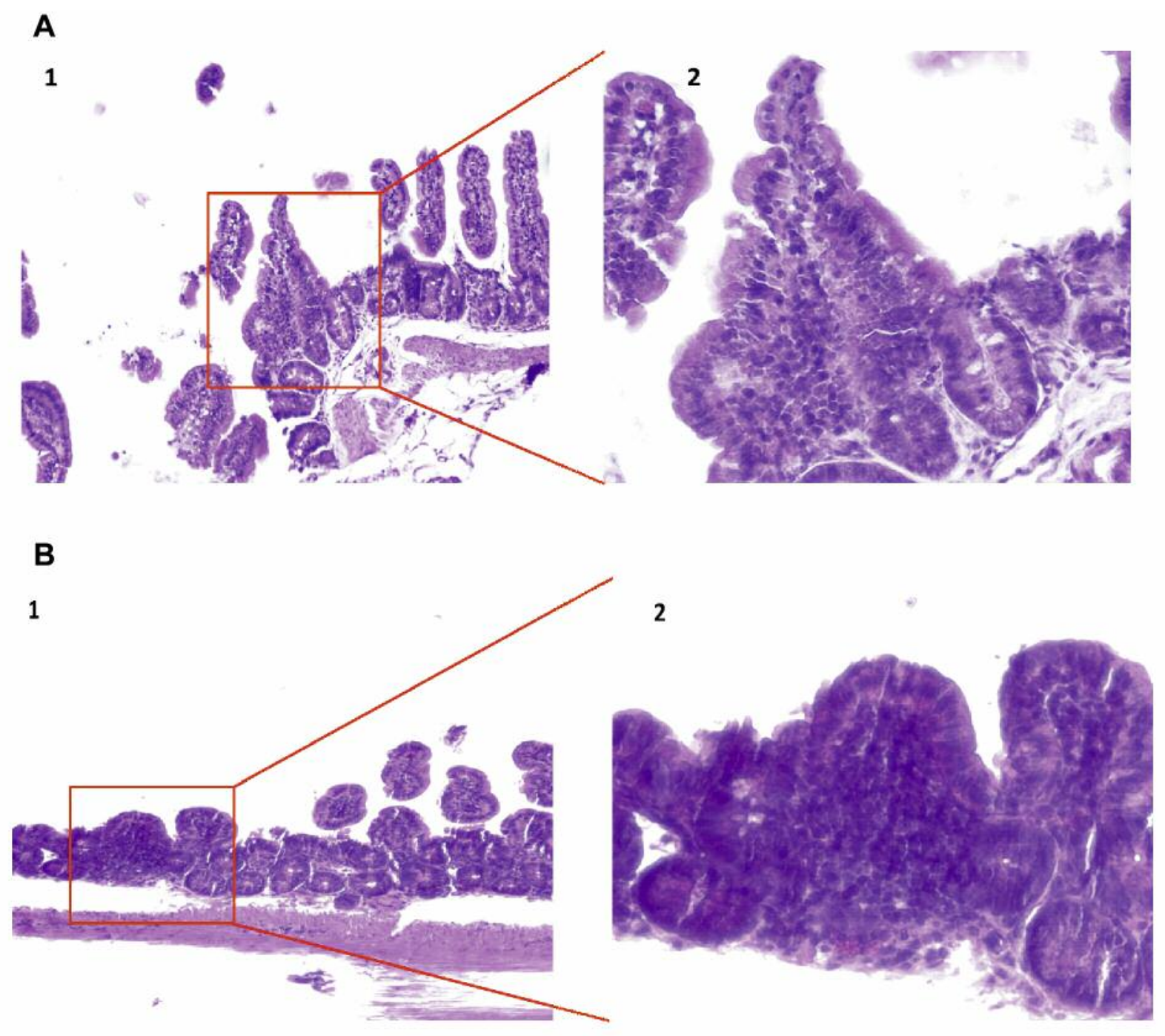

C

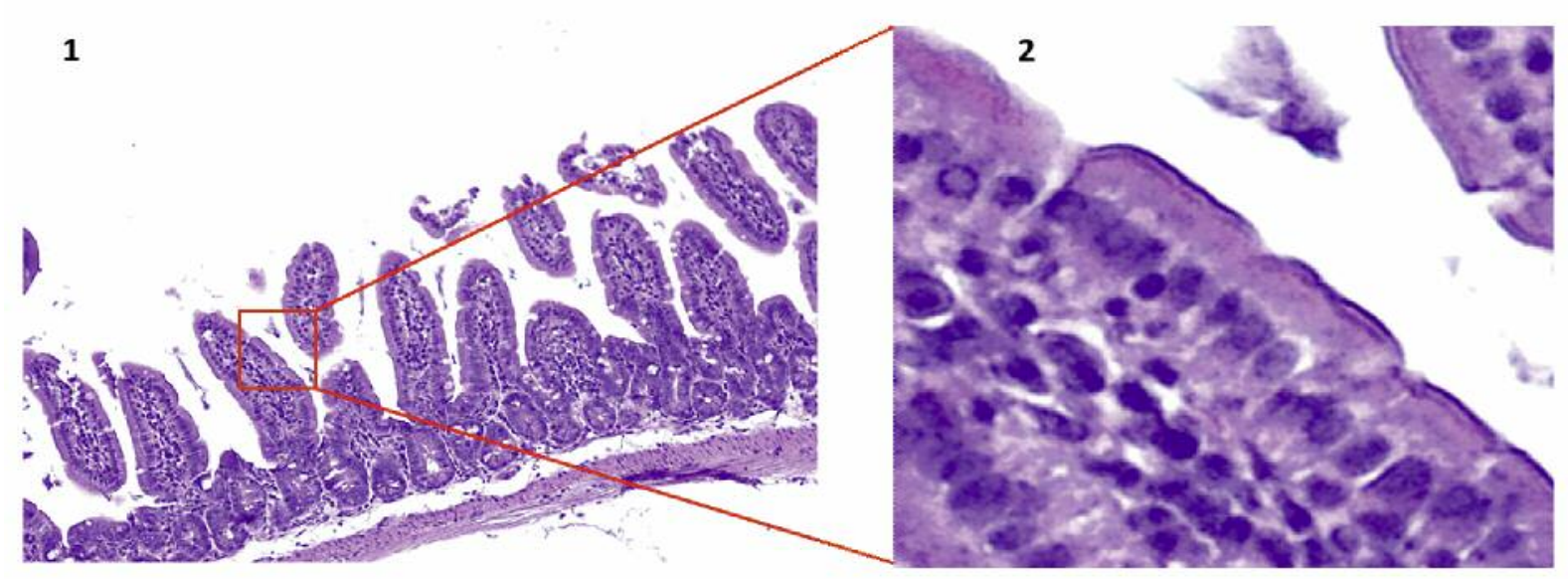

Figure 1. Histological characteristics of distal intestinal tissue with moderate dysplasia (A) and glandular structure mostly conserved with presence of an inflammatory infiltrate (B). Area without macroscopical lesions (normal tissue) (C). Magnification 20x in figures A1, B1 and C1 and 40x in Figures A2, B2 and C2. 

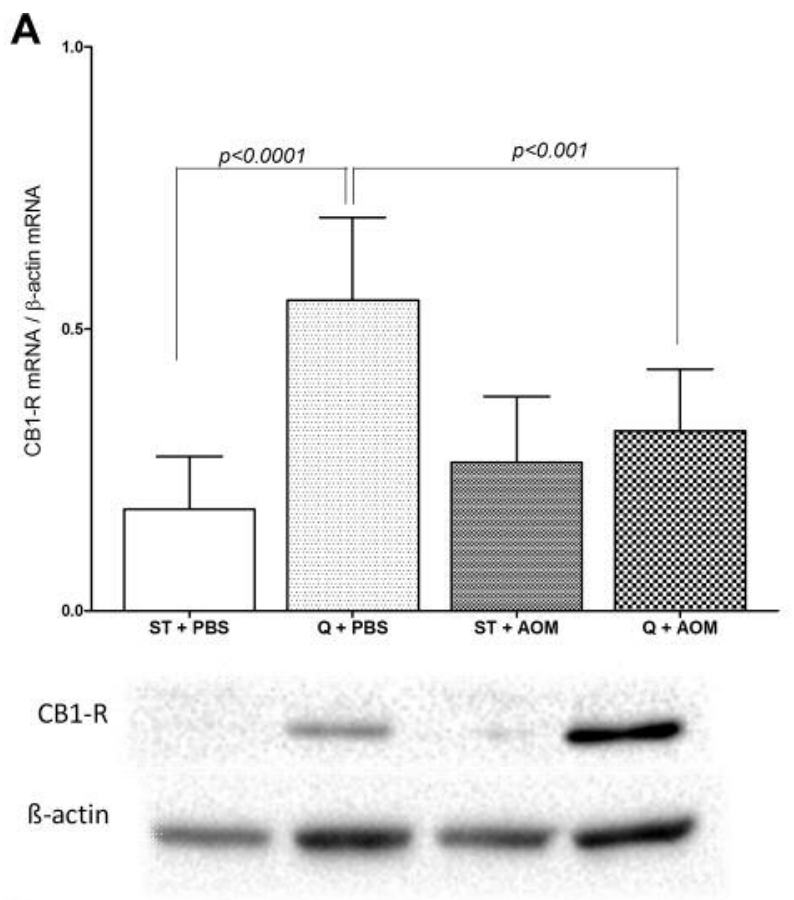

B

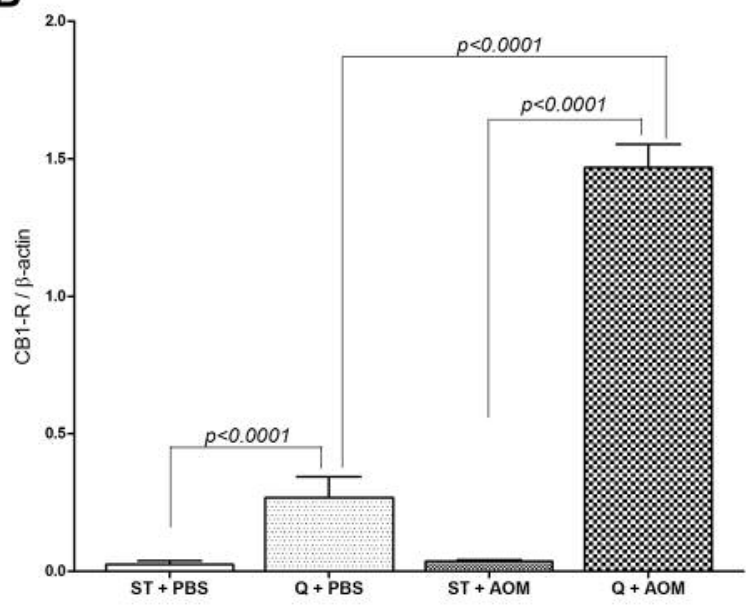

Figure 2. CB1-R mRNA (A) and protein (B) levels in intestinal tissue of 10 mice from each experimental group. A: Data are expressed as molecule numbers of CB1-R mRNA/molecule numbers of $\beta$-actin mRNA. B: Data are expressed as CB1-R protein expression levels normalized with $\beta$-actin protein expression. A p-value less than 0.05 was considered statistically significant using ANOVA and Tukey's Multiple Comparison. ST+PBS and $S T+A O M=$ control groups without and with $A O M$ injection; $Q+P B S$ and $Q+A O M=q u e r c e t i n$ treated mice groups without and with AOM injection.

\section{Discussion}

The anti-proliferative and pro-apoptotic effects of quercetin have been confirmed in many studies (20-22), but the novelty of the present study is certainly the finding demonstrating that the flavonoid quercetin protects against
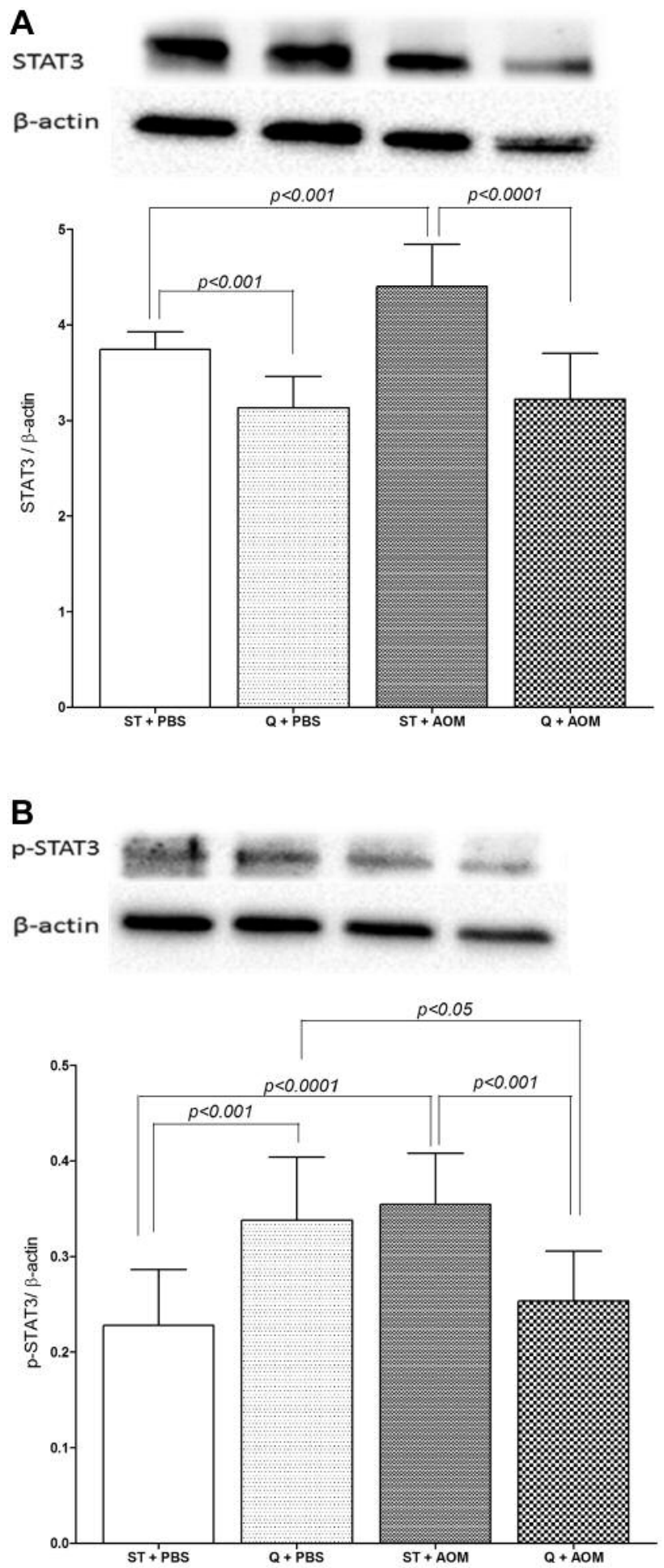

Figure 3. Western blotting analysis of expression of STAT3 (A) and pSTAT3 $(B)$ proteins in distal intestinal tissue of mice groups. A p-value less than 0.05 was considered statistically significant using ANOVA and Tukey's Multiple Comparison. ST+PBS and $S T+A O M=$ control groups without and with AOM injection; $Q+P B S$ and $Q+A O M=q u e r c e t i n$ treated mice groups without and with $A O M$ injection. 
A
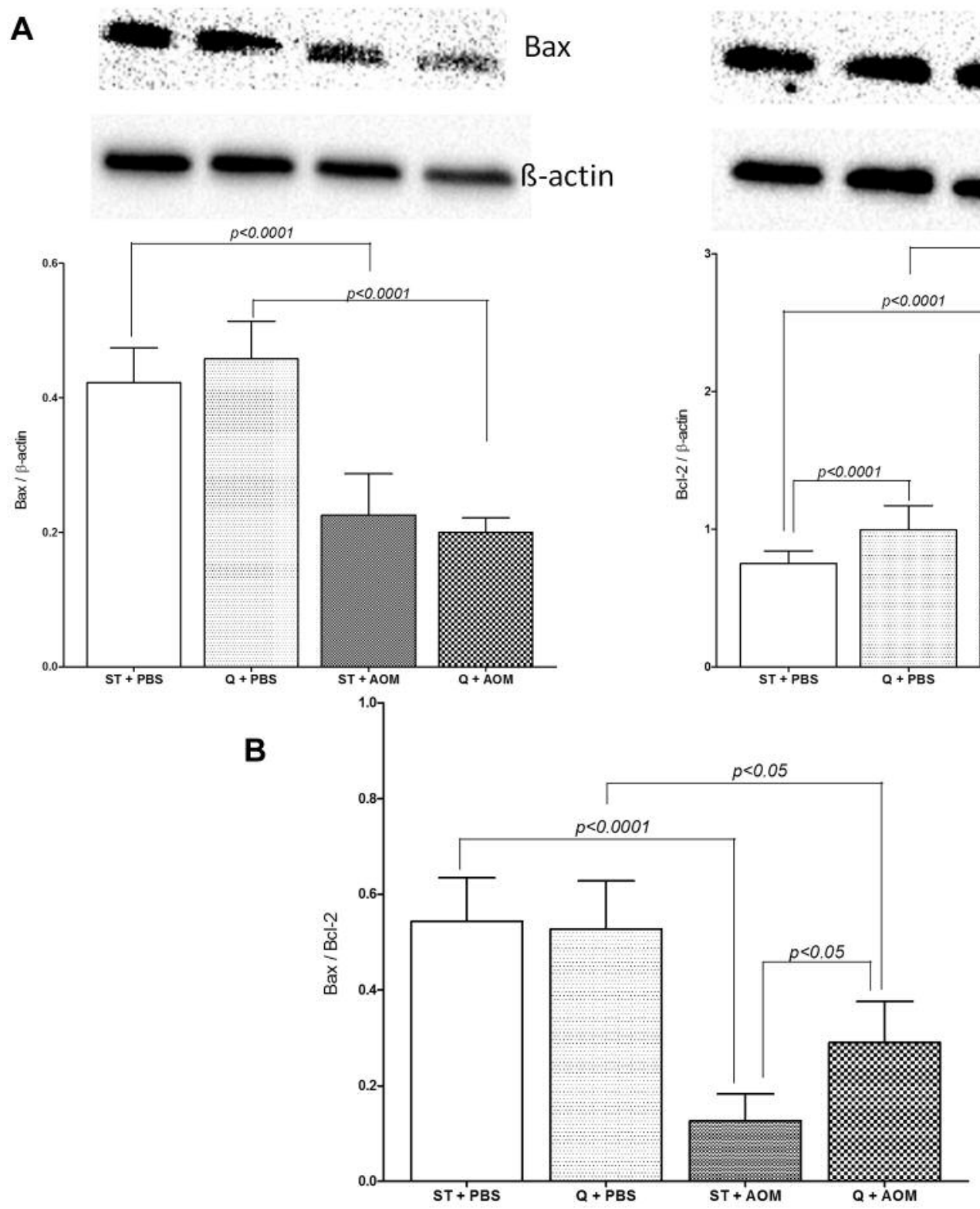
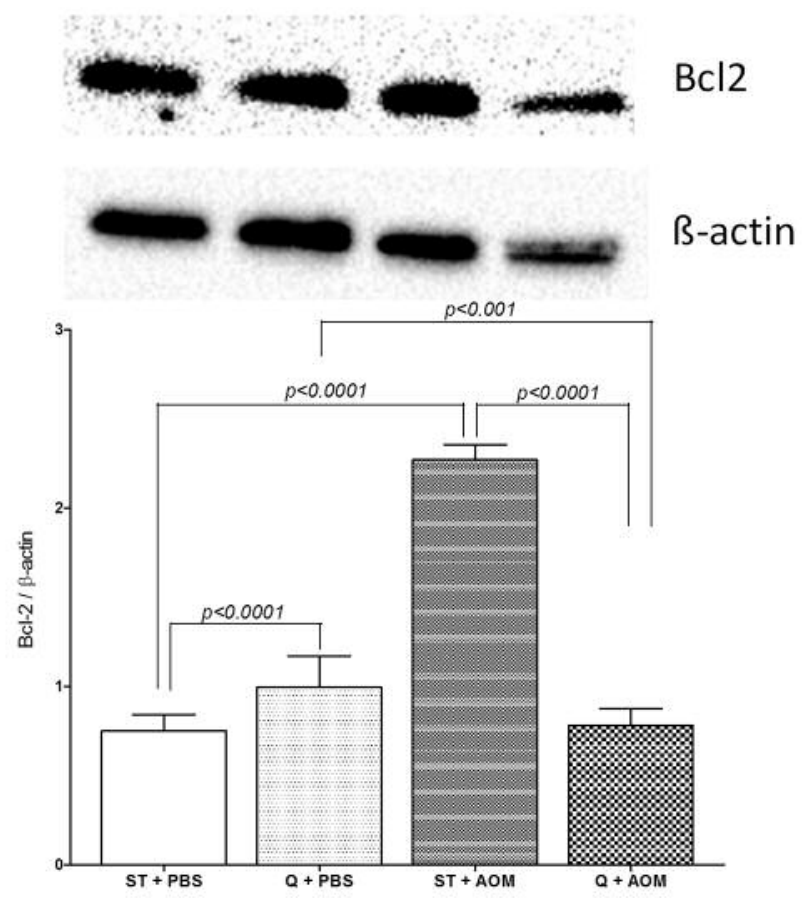

Figure 4. Western blot analysis of expression of Bax and Bcl2 proteins (A) in distal intestinal tissue ofmice groups and Bax/Bcl2 ratio protein expression (B). A p-value less than 0.05 was considered statistically significant using ANOVA and Tukey's Multiple Comparison. ST+PBS and $S T+A O M=$ control groups without and with $A O M$ injection; $Q+P B S$ and $Q+A O M=q u e r c e t i n$ treated mice groups without and with AOM injection.

tumor formation in a mouse model of CRC, by regulating the protein and the gene expression level of CB1-R.

Here, we histologically detected a low incidence of tumor lesions in our tissue samples and this finding is in agreement with other studies demonstrating a different susceptibility of murine species to AOM treatment (23). Several authors have shown that the C57BL/6 strain is among the species more resistant to this carcinogen (24-26) and therefore, the evaluation of histopathological and molecular features, as well as the study of the main genetic and epigenetic alterations involved in AOM induced carcinogenesis are needed in these mice.

In light of the alterations that occur in the pathogenesis of cancer in this experimental mouse model of CRC, the evaluation of CB1-R expression in our samples has confirmed the anti-cancer and cancer preventing action of quercetin. This finding is in accordance with our previous in vitro results, showing a crucial role of quercetin in the 
regulation of apoptosis, cell cycle signaling and cell migration (11). A role for CB1-R as a negative modulator of cell proliferation in colon cancer has been reported $(9,11)$. The colonic tumor growth seems to be facilitated by the absence of $\mathrm{CB} 1-\mathrm{R}$ and, in addition, the promoter hypermethylation of $\mathrm{CB} 1-\mathrm{R}$ gene $(C N R 1)$ has been demonstrated to contribute to colon carcinogenesis through silencing of the tumor-suppressing $C N R 1$ gene $(1,27)$.

The role of quercetin as an anti-cancer molecule is also confirmed by its ability to affect p-STAT3 expression, a biomarker of cell proliferation and aggressiveness. The inhibition of p-STAT3 by quercetin detected in AOM mice suggests that this natural compound, biologically active in a tumor-induced system, is able to protect colon tissue from cancer development.

Colon carcinogenesis, having a multistep nature, can be influenced by diet through the use of bioactive molecules able to influence tumor progression $(28,29)$. Our findings, confirming the preventive role of quercetin in colorectal cancer through CB1-R induction, are of great interest in light of developing novel therapeutic strategies for cancer treatment.

\section{Conflicts of Interest}

The Authors declare that they do not have any conflicts of interest regarding this work.

\section{Acknowledgements}

The Authors thank Vito Spilotro for his excellent technical assistance. This work was supported by Italian Ministry with RC/2017 and by "PO Puglia FESR 2007-2013, Asse I, Linea 1.2. Accordo di ProgrammaQuadro in materia di RicercaScientifica. Intervento "Reti di LaboratoriPubblici di Ricerca". Progetto L.A.I.F.F. - RETE DI LABORATORI PER L'INNOVAZIONE NEL CAMPO DEGLI ALIMENTI FUNZIONALI (codice n. 47)".

\section{References}

1 Wang D, Wang H, Ning W, Backlund MG, Dey SK and Dubois $\mathrm{RN}$ : Loss of cannabinoid receptor 1 accelerates intestinal tumor growth. Cancer Res 68: 6468-6476, 2008.

2 Massa $F$ and Monoroy K: Endocannabinoids and the gastrointestinal tract. J Endocrinol Invest 29: 47-57, 2006.

3 Izzo AA and Sharkey KA: Cannabinoids and the gut: new developments and emerging concepts. Pharmacol Ther 126: 2138, 2010.

4 Ladin DA, Soliman E, Griffin LT and van Dross R: Preclinical and clinical assessment of cannabinoids as anti-cancer agents. Front Pharmacol 7: 361, 2016.

5 Guzman M: Cannabinoids: potential anticancer agents. Nat Rev Cancer 3: 745-755, 2003.

6 Di Marzo V, Bifulco M and De Petrocellis L: The endocannabinnoids system and its therapeutic exploitation. Nat Rev Drug Discov 3: 771-784, 2004.
7 Izzo AA and Camilleri M: Cannabinoids in intestinal inflammation and cancer. Pharmacol Res 60: 117-125, 2009.

8 BifulcoM and Di MarzoV: Targeting the endocannabinoid system in cancer therapy: a call for further research. Nat Med 8: 547-550, 2002.

9 Notarnicola M, Messa C, Orlando A, Bifulco M, Laezza C, Gazzerro P and Caruso MG: Estrogenic induction of cannabinoid CB1 receptor in human colon cancer cell lines. Scand $J$ Gastroenterol 43: 66-72, 2008.

10 Linsalata M, Notarnicola M, Tutino V, Bifulco M, Santoro A, Laezza C, Messa C, Orlando A and Caruso MG: Effects of Anandamide on polyamine levels and cell growth in human colon cancer cells. Anticancer Res 30: 2583-2590, 2010.

11 Refolo MG, D'alessandro R, Malerba N, Laezza C, Bifulco M, Messa C, Caruso MG, Notarnicola $M$ and Tutino V: Anti proliferative and pro apoptotic effects of flavonoid quercetin are mediated by CB1 receptor in human colon cancer cell lines. J Cell Physiol 230: 2973-2980, 2015.

12 Di Francesco A, Falconi A, Di Germanio C, Micioni Di Bonaventura MV, Costa A,Caramuta S, Del Carlo M, Compagnone D, Dainese E, Cifani C, Maccarone M and D'Addario C: Extravirgin olive oil up-regulates CB1 tumorsuppressor gene in human colon cancercells and in rat colon via epigeneticmechanisms. J Nutr Biochem 26: 250-258, 2015.

13 Erlund I: Review of the flavonoids quercetin, hespeetin and naringenin. Dietary sources bioactivities, bioavailability and epidemiology. Nutr Res 24: 851-874, 2004.

14 Ramos S: Effects of dietary flavonoids on apoptotic pathways related to cancer chemoprevention. J Nutr Biochem 18: 427-442, 2007.

15 Ren MX, Li YH, Wu G, Ren JZ, Lu HB, Li ZM and Han XW: Quercetin nanoparticles display antitumor activity via proliferation inhibition and apoptosis induction in liver cancer cells. Int J Oncol 50: 1299-1311, 2017.

16 Hashemzaei M, Delarami Far A, Yari A, Heravi RE, Tabrizian K, Taghdisi SM, Sadegh SE, Tsarouhas K, Kouretas D, Tzanakakis G, Nikitovic D, Anisimov NY, Spandidos DA, Tsatsakis AM and Rezaee R: Anticancer and apoptosis-inducing effects of quercetin in vitro and in vivo. Oncology Reports 38 : 819-828, 2017.

17 Warren CA, Paulhill KJ, Davidson LA, Lupton JR, Taddeo SS, Hong MY, Carrol RJ, Chapekin RS and Turner ND: Quercetin may suppress rat aberrant crypt foci formation by suppressing inflammatory mediators that influence proliferation and apoptosis. J Nutr 139: 101-105, 2009.

18 Johnson IT: Anticarcinogenetic effects of diet-related apoptosis in the colorectal mucosa. Food Chem Toxicol 40: 1171-1178, 2002.

19 Turner ND, Paulhill KJ, Warren CA, Davidson LA, Chapkin RS and Lupton JR: Quercetin suppresses early colon carcinogenesis partly through inhibition of inflammatory mediators. Acta Hortic 841: 237-242, 2009.

20 Yoshida M, Sakai T, Hosokawa N, Marui N, Matsumoto K, Fujioka A, Nishino $\mathrm{H}$ and Aoike A: The effect of quercetin on cell cycle progression and growth of human gastric cancer cells. FEBS Lett 260: 10-13,1990.

21 Murakami A, Ashida $\mathrm{H}$ and Terao J: Multitargeted cancer prevention by quercetin. Cancer Lett 269: 315-325, 2008. 
22 Nuyen TT, Tran E, Nguyen TH, Do PT, Huynh TH and Huynh $\mathrm{H}$ : The role of activated MEK-ERK pathway in quercetininduced growth inhibition and apoptosis in A549 lung cancer cells. Carcinogenesis 25: 647-659, 2004.

23 De Robertis M, Massi E, Poeta ML, Carotti S, Morini S, Cecchetelli L, Signori E and Fazio VM: The AOM/DSS murine model for the study of colon carcinogenesis: from pathways to diagnosis and therapy studies. J Carcinog 10: 9, 2011.

24 Suzuki R, Kohno H, Sugie S, Nakagama H and Tanaka T: Strain differences in the susceptibility to azoxymethane and dextran sodium sulfate-induced colon carcinogenesis in mice. Carcinogenesis 27: 162-169, 2006.

25 Papanikolaou A, Wang QS, Papanikolaou D, Whiteley HE and Rosenberg DW: Sequential and morphological analyses of aberrant crypt foci formation in mice of differing susceptibility to azoxymethane-induced colon carcinogenesis. Carcinogenesis 21: $1567-1572,2000$.

26 Bissahoyo A, Pearsall RS, Hanlon K, Amann V, Hicks D, Godfrey VL and Threadgill DW: Azoxymethane is a genetic backgrounddependent colorectal tumor initiator and promoter in mice: effects of dose, route and diet. Toxicol Sci 88: 340-345, 2005.
27 Hasenoehrl C, Feuersinger D, Sturm EM, Bärnthaler T, Heitzer E, Graf R, Grill M, Pichler M, Beck S, Butcher L, Thomas D, Ferreirós N, Schuligoi R, Schweiger C, Haybaeck J and Schicho R: G protein-coupled receptor GPR55 promotes colorectal cancer and has opposing effects to cannabinoid receptor 1 . Int $\mathrm{J}$ Cancer 142: 121-132, 2017.

28 Notarnicola M, Tutino V, Tafaro A and Caruso MG: Antitumorigenic effect of dietary natural compounds is via lipid metabolism modulation in ApcMin/+ mice. Anticancer Res 33: 3739-3744, 2013.

29 Tutino V, De Francesco ML, Tolomeo M, De Nunzio V, Lorusso D, Paleni D, Caruso MG, Notarnicola M and Barile M: The expression of riboflavin transporters in human colorectal cancer. Anticancer Res 38: 2659-2667, 2018.

Received June 7, 2018

Revised June 15, 2018

Accepted June 18, 2018 